\title{
Influence of Abrasive Water Jet (AWJ) on Surface Roughness
}

\author{
Ameer J. Nader and Saad K. Shather
}

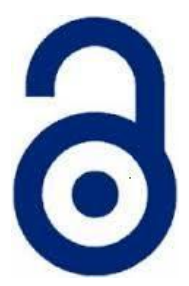

Received: 27 February 2021

Accepted: 01 May 2021

Published: 15 July 2021

Publisher: Deer Hill Publications

(c) 2021 The Author(s)

Creative Commons: CC BY 4.0

\begin{abstract}
Abrasive water jet (AWJ) is one of the most advanced and valuable non-traditional machining processes because of its massive advantages of removing metals ranging from hard to soft. This paper focused on studying the influence of jet pressure, feed rate and standoff distance on surface roughness during cutting carbon steel using abrasive water jet cutting. A surface roughness device assessed the surface roughness by performing sixteen experiments to identify the distinct texture of the surface. Based on the experiences, the best surface roughness value was $3.14 \mu \mathrm{m}$ at jet pressure $300 \mathrm{MPa}$, standoff distance $4 \mathrm{~mm}$ and feed rate $30 \mathrm{~mm} / \mathrm{min}$. The Taguchi method was introduced to implement the experiments and indicate the most influential process parameters on average surface roughness. The experimental results reveal that feed rate has a significant effect on average surface roughness.
\end{abstract}

Keywords: Abrasive water jet, Feed rate, Surface roughness, Carbon steel.

\section{INTRODUCTION}

Abrasive water jet (AWJ) cutting machine is one of the most superior modern machining technologies utilized in the manufacturing industry for material processing. Abrasive water jet (AWJ) cutting is a non traditional machining technology [1-2]. AWJ cutting operation is based on the material erosion by high-speed water jet with abrasive particles [3]. AWJ cutting process is a powerful technology for machining different engineering materials and a wide range of thicknesses. AWJ cutting is broadly utilized in machining materials such as brass, aluminum, titanium, steel, Inconel, stone, and any composites and glass [4-6]. No heat-affected zone, ability to machine a wide range of materials, non-contact of the tool with a workpiece and low machining force on the work surface has raised the use of abrasive water jet machining over other machining processes. [7-8]. The influence of machining parameters on the surface topography and surface roughness of titanium metal by AWJ was studied and identified the parameters which affects the surface roughness. It was observed that the standoff distance had proportional relationship with average surface roughness [9]. The effect of AWJ machining parameters such as jet pressure, and standoff distance on surface roughness of brass 360 was investigated. They found that the water jet pressure as the most influential factor related to surface roughnes [10]. Taguchi method is the most suited method to identify the optimized parameter with the reduced number of experiments without altering its quality [11-12]. The Taguchi experiment method was used to conduct an analysis based on a study of average surface roughness in abrasive water jet (AWJ) cutting of cast iron metal. Transverse speed, water pressure, standoff distance and material feed rate are all known as process parameters that affect the roughness of the surface. The most crucial factor influencing surface roughness was water pressure, which had an inverse proportional relation with average surface roughness [13]. The influence of AWJ process parameters such as water pressure, nozzle traverse speed, abrasive mass flow rate and standoff distance on surface roughness $(\mathrm{Ra})$ of aluminium was studied . was studied The result indicate that the use of high water pressure and low standoff distance is preferred to obtain good surface finish [14]. The Taguchi method based Analysis of variance (ANOVA) was proposed to optimize the Abrasive Water Jet Machining process parameters to decrease average surface roughness. The importance of process parameters was achieved through variance analysis based on the $\mathrm{L} 9$ orthogonal array, which revealed the most important parameters being feed rate [15].

Many researchers have been carried out on various parameters of AWJM. Little literature was available on influence standoff distance, pressure jet, and Feed rate on average surface roughness and dimensional accuracy. The present study highlights experimentally the influence of metal cutting variables such as Pressure jet, feed rate and standoff distance on the surface roughness through the abrasive jet machining of the Carbon steel alloy.

Ameer J. Nader and Saad K. Shather

Production and Metallurgy Engineering Department

University of Technology, Iraq - Baghdad

E-mail: pme.19.17@grad.uotechnology.edu.iq

References: Ameer and Saad (2021). Influence of Abrasive Water Jet (AWJ) on Surface Roughness. International Journal of Engineering Materials and Manufacture, 6(3), 132-140. 


\section{MATERIAL}

Abrasive water jet (AWJ) experiences were carried out on a sample of carbon steel of $(10 \times 40 \times 118)$ mm dimensions with the following chemical composition according to the standard BS EN10025-2:

Table 1: Chemical composition of carbon steel (measured).

\begin{tabular}{cccccccccccc}
\hline $\mathrm{C} \%$ & $\mathrm{Mn} \%$ & $\mathrm{Si} \%$ & $\mathrm{P} \%$ & $\mathrm{Cu} \%$ & $\mathrm{Mo} \%$ & $\mathrm{Cr} \%$ & $\mathrm{~S} \%$ & $\mathrm{AL} \%$ & $\mathrm{Co} \%$ & $\mathrm{Ni} \%$ & $\mathrm{Fe} \%$ \\
\hline 0.14 & 1.30 & 0.47 & 0.028 & 0.18 & 0.045 & 0.16 & 0.017 & 0.004 & 0.012 & 0.15 & 97.4 \\
\hline
\end{tabular}

Carbon steel is non-alloy steel in which carbon is a fundamental component that determines its grade. Carbon steel is strong, good formability and wedability, shock-resistant, and strengthening by coldwork; this metal is often the most practical choice. And it is widely used in various fields for various purposes such as constructing bridges and buildings, automobile industries and oil indistry [4]. According to BS EN 10025-2, the sample has the name and number $5355 \mathrm{~J} 2$ and 1.0577, respectively, in addition to the following mechanical properties:

Table 2: mechanical properties of carbon steel (measured).

\begin{tabular}{cccc}
\hline Yield strength $(\mathrm{MPa})$ & Tensile strength (MPa) & \multicolumn{2}{c}{ Elongation after fracture (mm) } \\
\hline 355 & 470 to 630 & 221 & $20 \mathrm{t}$ \\
\hline
\end{tabular}

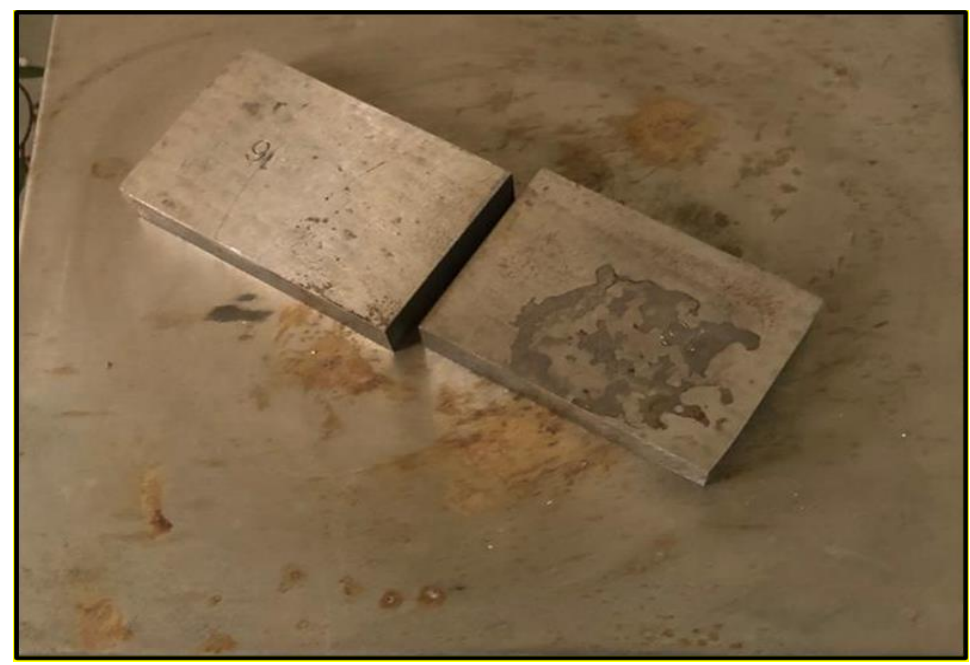

Figure 1: Photograph of the carbon steel workpiece

\section{MACHINE}

The experimental setup for the abrasive water jet machine (Model No. 3020; YONODA, China) is shown in figure 2. The machine uses a 3-stage plunger-type high-pressure pump that can generate high pressures up to $413 \mathrm{MPa}(60$ $000 \mathrm{psi})$. The machine has a water discharge capacity of 2.6 litres/min at this rated pressure. The maximum traverse speed of the machine is limited to $1200 \mathrm{~mm} / \mathrm{min}$ and the motion is controlled by a CNC, a motorized Z-axis for vertical movement. The working and technical specifications of the machine are given in Table 3 .

All the experiments were conducted at $90^{\circ}$ jet impingement angles only. The cutter head consists mainly of two nozzles, one of them is primary (jewel orifice) and the other is secondary (Focusing or mixing tube). The primary nozzle is the orifice in which exits water form the cutting stream. Typically jewels are created from ruby, diamond, or sapphire, a "jewel" mounted in a steel insert. Its diameter ranges from 0.007 " to 0.020 " $(0.178-0.51) \mathrm{mm}[16]$, notice figure 3. Secondary nozzle Sometimes refers to as mixing tube or Focusing tube. This is a tube manufactured from a tough material that concentrates the water and abrasive into a coherent beam for cutting. Typically, a mixing tube has a diameter of $0.030 "(0.76 \mathrm{~mm})$ [16], notice figure 3 , to the abrasive water jet nozzle to cut efficiently and improve the life of components. The jewel orifice must be accurately aligned in the nozzle body.

After the pure water jet is formed, abrasives are added utilizing either the suspension or injection methods as shown in Figure 4. The significant parameters of the abrasives are the mechanical behavior, the material structure and hardness, grain size, grain shape, and distribution [17]. 


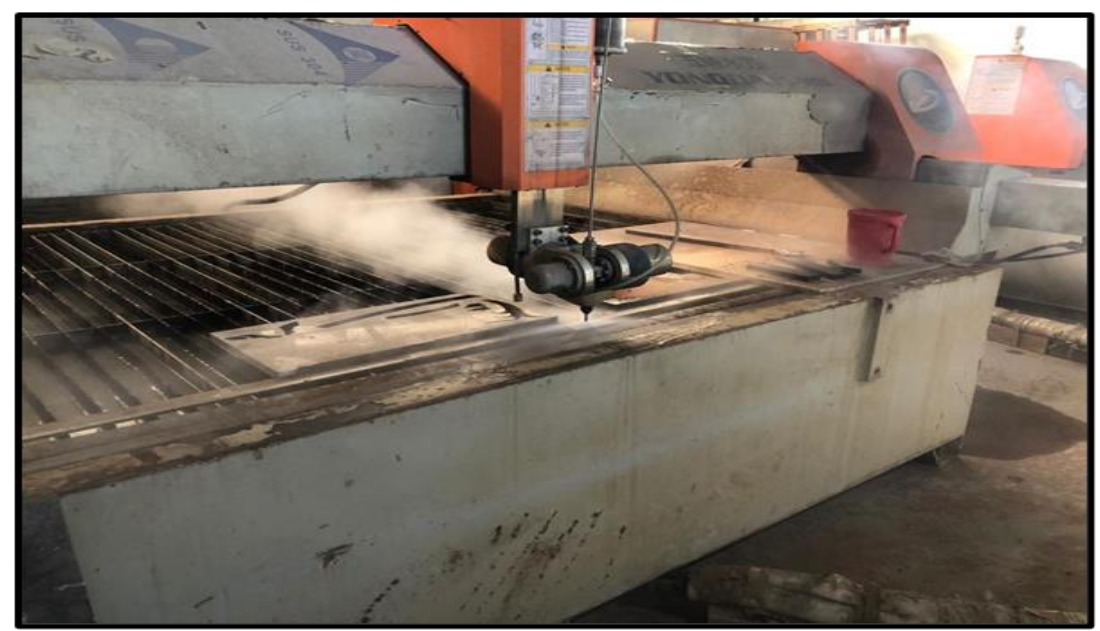

Figure 2: Experimental setup for abrasive water jet machining.

Table 3: Technical Specifications of AWJM

\begin{tabular}{ll}
\hline Machine & YONODA, China \\
\hline Maximum transverse speed & $1200 \mathrm{~mm} / \mathrm{min}$ \\
\hline Impact angle & $90^{\circ}$ \\
\hline Mixing Tube Length & $76.2 \mathrm{~mm}$ \\
\hline Focusing/Mixing Tube Diameter & $1.02 \mathrm{~mm}$ \\
\hline Orifice Diameter & $0.3 \mathrm{~mm}$ \\
\hline Maximum Working Pressure & $413 \mathrm{MPa}$ \\
\hline Maximum distance from the workpiece & $10 \mathrm{~mm}$ \\
\hline Table size & $2000 \times 3000 \mathrm{~mm}$ \\
\hline Operation program & Nc studio V10 \\
\hline
\end{tabular}

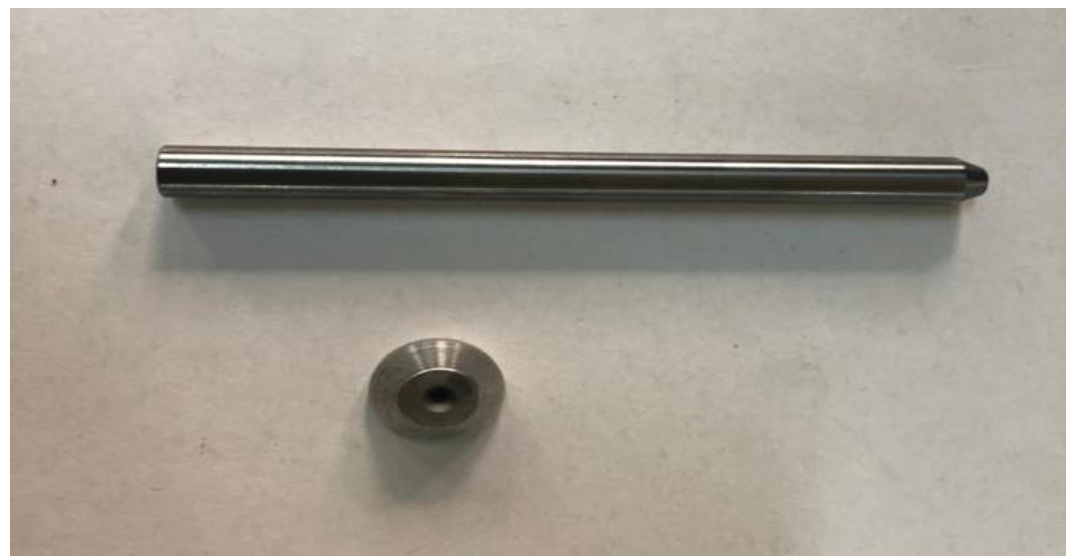

Figure 3: Orifice and mixing tube. 
Red garnet 80 mesh with an average particle size of $0.180 \mu \mathrm{m}$ is used as an abrasive material throughout the experiment, which is the most popular kind of abrasive utilized in AWJ cutting machine because of the following facts. (1) It is widely available, thus relatively inexpensive. (2) It is an inert material that does not interact with the material to be cut. (3) When hitting the target, it breaks down, forming sharp edges, thus making better cutting performance. [18].
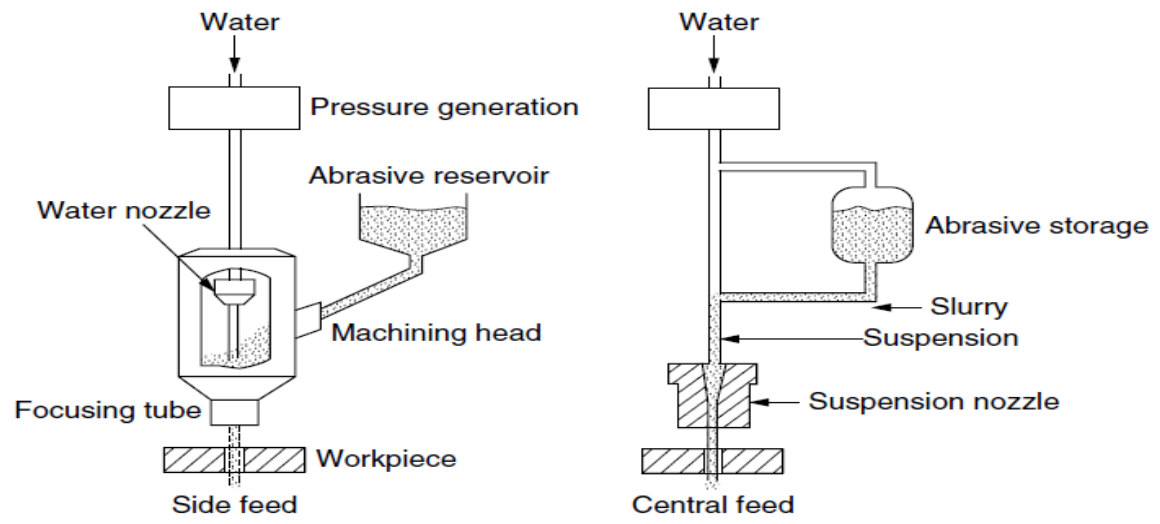

Figure 4: injection and suspension system [17].

\section{EXPERIMENTAL PROCEDURE}

The machining was done by considering the jet pressure, standoff distance and feed rate and each process parameter were varied over four levels, as shown in Table 4. Based on the Taguchi's design philosophy, standard orthogonal array L16, as shown in Table 5, has been selected to complete the experiment and to estimate its impacts on surface roughness. Cutting was performed on a sample of carbon steel having dimensions $(10 \times 40 \times 118) \mathrm{mm}$. After machining was completed, Surface roughness on the cut surface was measured in terms of the average roughness Ra, using a surface roughness measuring device at various zones of the cut surface.

Table 4: Process control parameters and levels

\begin{tabular}{lccccc}
\hline Parameter & Units & Level I & Level II & Level III & Level IV \\
\hline Pressure jet & $\mathrm{MPa}$ & 225 & 250 & 275 & 300 \\
Feed rate & $\mathrm{mm} / \mathrm{min}$ & 30 & 50 & 70 & 90 \\
Standoff distance & $\mathrm{mm}$ & 1 & 2 & 3 & 4 \\
\hline
\end{tabular}

Table 5: experimental design

\begin{tabular}{|c|c|c|c|}
\hline No. & Pressure (MPa) & Feed Rate (mm/min) & $\begin{array}{c}\text { Standoff Distance } \\
(\mathrm{mm})\end{array}$ \\
\hline $\mathbf{1}$ & 225 & 30 & 1 \\
\hline $\mathbf{2}$ & 225 & 50 & 2 \\
\hline $\mathbf{3}$ & 225 & 70 & 3 \\
\hline 4 & 225 & 90 & 4 \\
\hline 5 & 250 & 30 & 2 \\
\hline 6 & 250 & 50 & 1 \\
\hline $\mathbf{7}$ & 250 & 70 & 4 \\
\hline 8 & 250 & 90 & 3 \\
\hline 9 & 275 & 30 & 3 \\
\hline 10 & 275 & 50 & 4 \\
\hline 11 & 275 & 70 & 1 \\
\hline 12 & 275 & 90 & 2 \\
\hline 13 & 300 & 30 & 4 \\
\hline 14 & 300 & 50 & 3 \\
\hline 15 & 300 & 70 & 2 \\
\hline 16 & 300 & 90 & 1 \\
\hline
\end{tabular}




\section{MEASUREMENT OF SURFACE ROUGHNESS}

Roughness is the measure of the texture of a machined surface. It is quantified by vertical deviation of the real surface. Roughness is usually defined as a measured surface's high-frequency short wavelength. The abrasive water jet experiments were conducted on carbon steel based on Taguchi's L16 orthogonal array using jet pressure, feed rate and standoff distance.

There are several techniques employed to measure surface roughness. The method adopted to measure the surface roughness during the present investigation is $\mathrm{Ra}$ (the Arithmetic Mean of the peaks and valleys from the mean line through a sampling length). It is the most widely used and internationally employed parameter for the measurement of surface roughness. This method can be defined by the mean deviations present above and below the mean plane of the surface measured within a certain distance. It is referred to ( $\mathrm{Ra}$ ) and can be calculated from the following equation [19]:

$$
R_{a}=\frac{1}{l_{m}} \int_{x=0}^{x=l_{m}}|y| d x
$$

Where $I m$ is the profile length used for parameter evaluation, $y$ is the ordinate of the centerline profile, as shown in figure 5 .

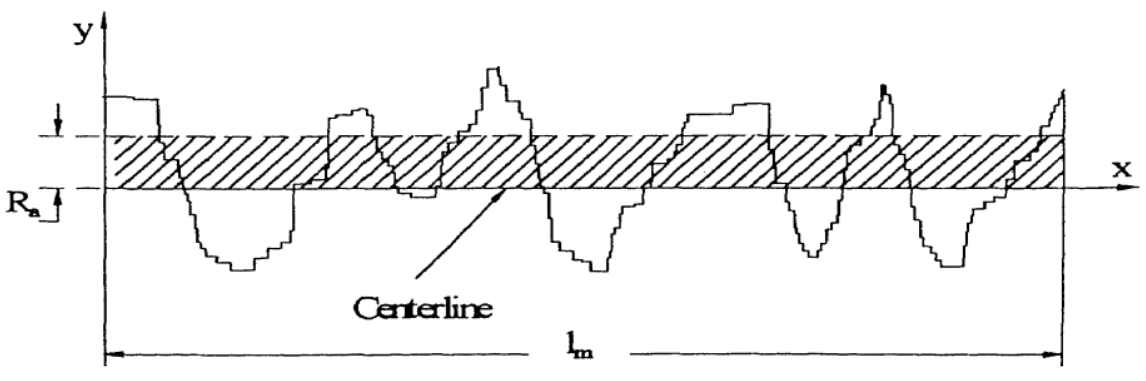

Figure 5: Roughness Average ( $\mathrm{Ra})[18]$.

The portable electronic device (Pocket Surf III) is used to measure the surface roughness as shown in figure 6, where traversing length (10) $\mathrm{mm}$, measuring a range of $(0.3-6.35) \mu \mathrm{m}$ and accuracy $( \pm 0.05) \mu \mathrm{m}$. The average surface roughness is calculated using four readings of the roughness from the surface of the machined workpiece and take the average of these readings as the final value of the average surface roughness.

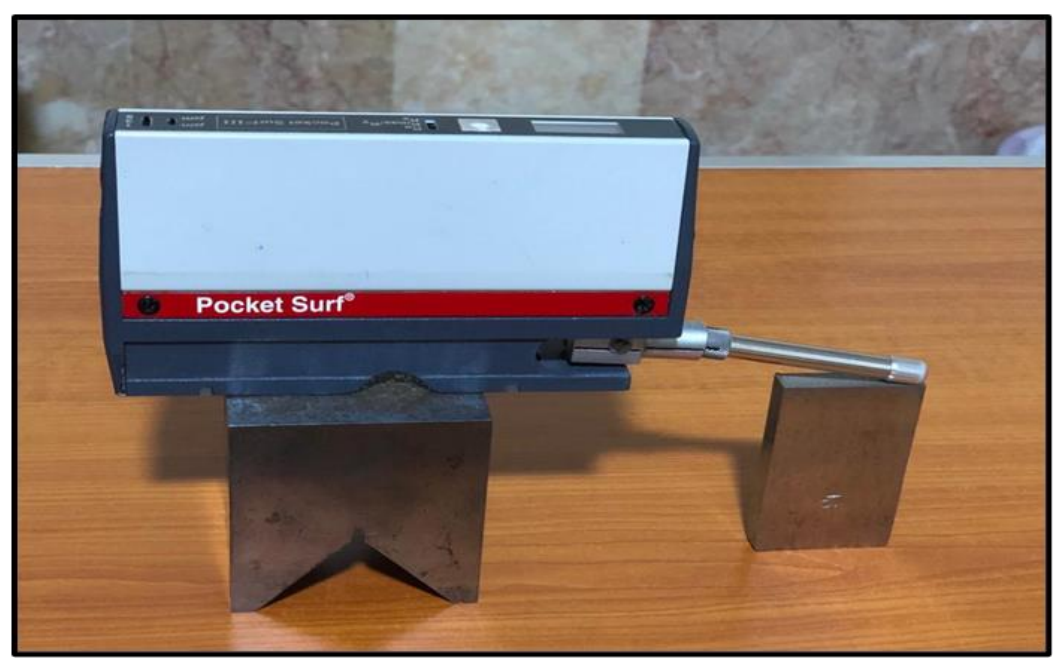

Figure 6: Photo of the Surface roughness measuring device. 


\subsection{The Design of Experiments (DOE)}

The method of designing experiments when taking into account process parameters at different levels is known as design of experiments (DOE). Taguchi's method for experimental design offers a simple, systematic, and efficient approach for determining the efficiency, expense, and quality of an experiment (Aydin et al., 2010). Statistically designed experiments are conducted more efficiently as they consider many parameters simultaneously. They can identify significant interactions with a minimum number of experiments, unlike conventional experimentation, A complete factorial experimental set consisting of abrasive strain, standoff distance, and feed rate as process parameters, each at 4-levels with all possible combinations, totaling 16 experiments, was chosen based on the above. The process parameters range is specified in Table 5.

\subsection{Analysis Data}

MINITAB is a widely used mathematical software program in fields such as statistics, mathematics, sports, economics, and engineering. It is highly interactive program that allows data entry, ANOVA analysis, regression analysis, DOE design, reliability/survival tests, taguchi analysis, drawing control charts for processes, plotting time series plots, multivariate tests, and other tasks very simple and time-saving. It is the most effective method for quality improvement initiatives based on results. MINITAB (version 17) was used in this study for ANOVA analysis and plotting various graphs [20].

In the analysis of variance (ANOVA), the $\mathrm{F}$ ratio was applied to calculate the important process parameter on the material removal rate and average surface roughness. An $\mathrm{F}$ ratio is estimated from the experimental results and then compared to the critical value. If the $\mathrm{F}$ ratio estimated is larger than the $\mathrm{F}$ critical value, it is an indication that the statistical test is important at the confidence level selected [21].

In this work, an analysis of variance was carried out for the confidence level of $96.1 \%$. It was found that the factors feed rate $(t)$ and pressure $(p)$ was the most significant factor impacting the assessment of the average surface roughness. To observe the impact of important factors, the results of the response parameters are displayed through graphs. The experimental tests are designed for four levels and three parameters.

\section{RESULTS}

In this section, the influence of the process parameters such as jet pressure, feed rate and standoff distance on the surface roughness during AWJ cutting of carbon steel was examined.

Table 6 shows the predicted and measured results of surface roughness for the target material samples by (Taguchi design). Figure 7 explains the Main effects plot of process parameters on the surface roughness. Four readings of surface roughness for each specimen were recorded and the average of them was taken for the workpiece.

The predicted average surface roughness values were compared with the measured values, as presented in Table 6. The results of the surface roughness ( $\mathrm{Ra}$ ) were close between predicted and measured. The ability of independent value to predict the surface roughness was (96.1\%). This means that the correlation coefficient between the dependent variable's measured value and the expected value is good

Table 6: Measured and predicted surface roughness

\begin{tabular}{|c|c|c|c|c|c|}
\hline No. & $\begin{array}{c}\text { Pressure } \\
(\mathrm{MPa})\end{array}$ & $\begin{array}{c}\text { Feed Rate } \\
(\mathrm{mm} / \mathrm{min})\end{array}$ & $\begin{array}{c}\text { Standoff distance } \\
(\mathrm{mm})\end{array}$ & $\begin{array}{c}\text { Measured Ra } \\
(\mu \mathrm{m})\end{array}$ & $\begin{array}{c}\text { Predicted Ra } \\
(\mu \mathrm{m})\end{array}$ \\
\hline 1 & 225 & 30 & 1 & 3.46 & 3.46 \\
\hline 2 & 225 & 50 & 2 & 4.10 & 4.03 \\
\hline 3 & 225 & 70 & 3 & 4.08 & 4.26 \\
\hline 4 & 225 & 90 & 4 & 4.86 & 4.74 \\
\hline 5 & 250 & 30 & 2 & 3.38 & 3.44 \\
\hline 6 & 250 & 50 & 1 & 3.86 & 3.85 \\
\hline 7 & 250 & 70 & 4 & 4.37 & 4.29 \\
\hline 8 & 250 & 90 & 3 & 4.51 & 4.52 \\
\hline 9 & 275 & 30 & 3 & 3.29 & 3.19 \\
\hline 10 & 275 & 50 & 4 & 3.64 & 3.80 \\
\hline 11 & 275 & 70 & 1 & 3.89 & 3.80 \\
\hline 12 & 275 & 90 & 2 & 4.21 & 4.23 \\
\hline 13 & 300 & 30 & 4 & 3.14 & 3.16 \\
\hline 14 & 300 & 50 & 3 & 3.62 & 3.52 \\
\hline 15 & 300 & 70 & 2 & 3.74 & 3.72 \\
\hline 16 & 300 & 90 & 1 & 3.91 & 3.99 \\
\hline
\end{tabular}




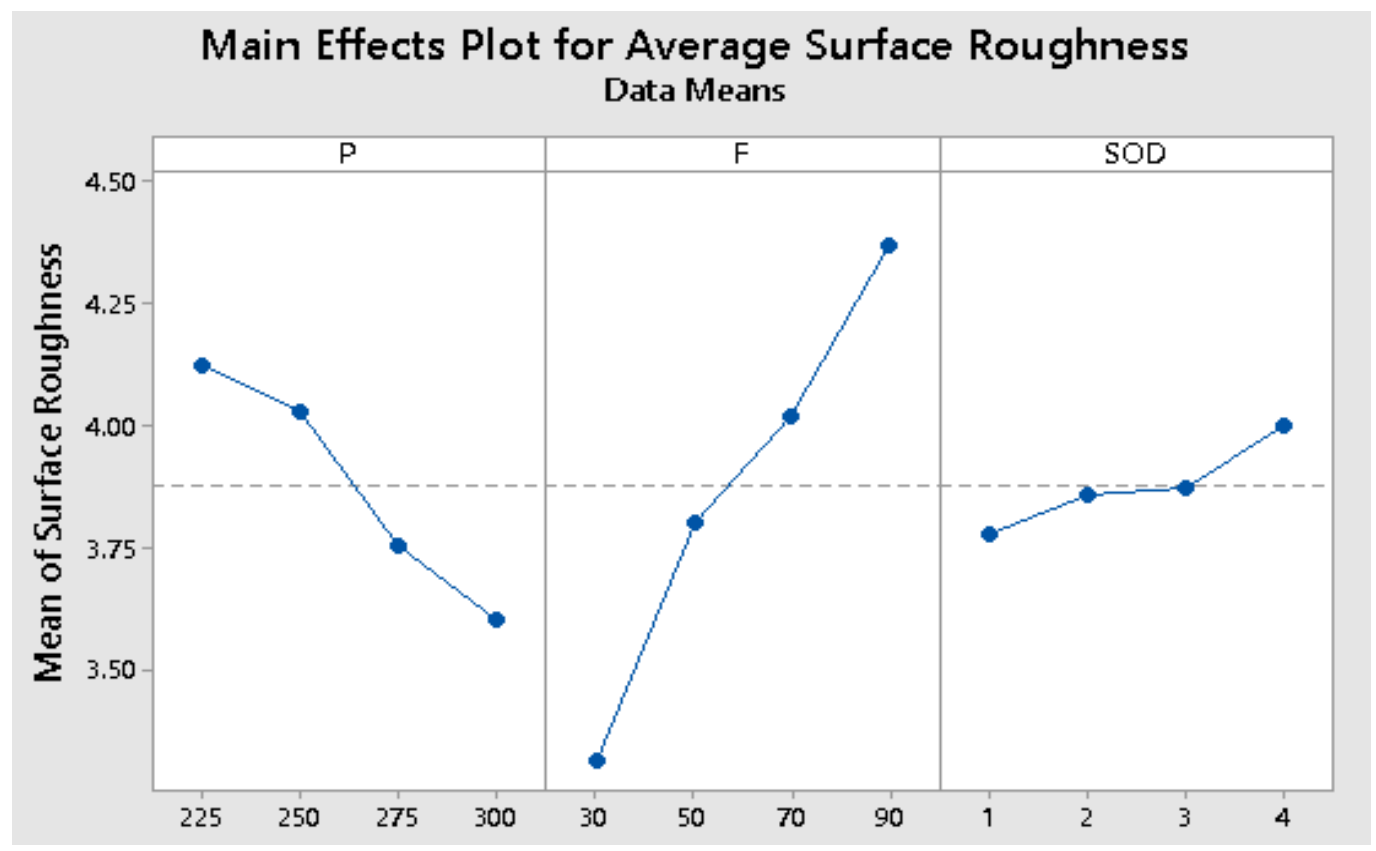

Figure 7: Main influence for average surface roughness.

\subsection{Influence of Jet Pressure on The Average Surface Roughness}

By conducting experiments, it's observed that average surface roughness decreases from 4.86 to $3.14 \mu \mathrm{m}$ when increasing the pressure from 225 to $300 \mathrm{MPa}$, as shown in figure 8, taking into consideration the standoff distance. It is seen that the average surface roughness improves with a rise in hydraulic pressure up (inverse relationship). A raise in the jet pressure causes a rise in the kinetic energy of the abrasive particles to the maximum level, brittle abrasives break down into smaller ones. This result decreases the waves developed on the machined surface. Consequently, it produces a smooth finish with a decrease in the surface roughness value [10].

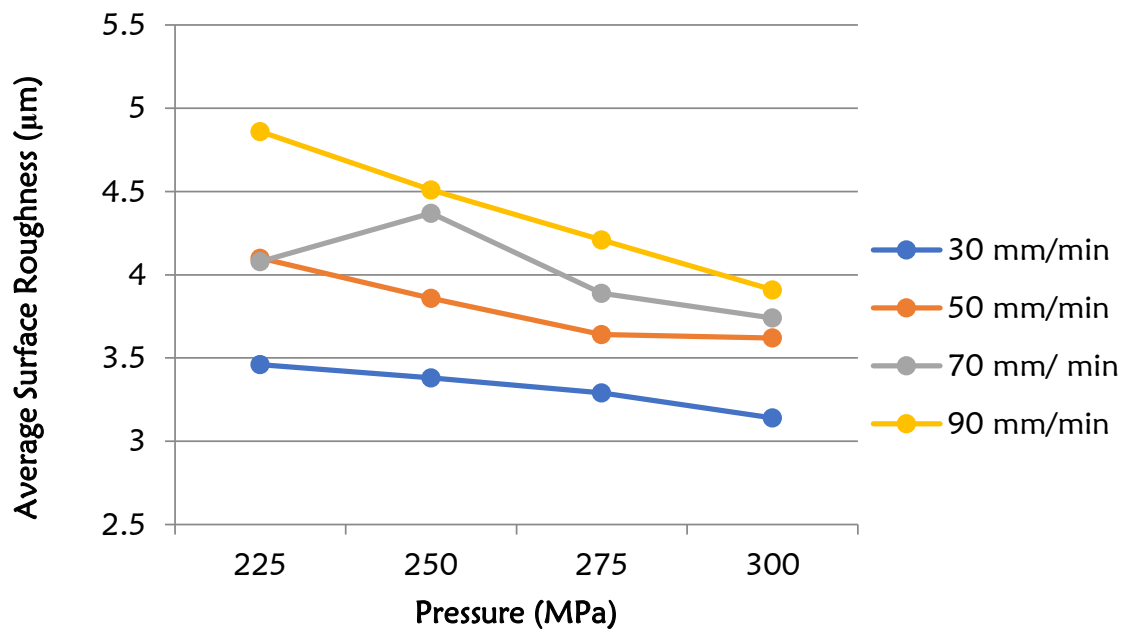

Figure 8: A plot of influence of jet pressure on the average surface roughness (Ra). 


\subsection{Influence of Feed Rate on The Average Surface Roughness}

By conducting experiments, it's observed that average surface roughness increases from 3.14 to $4.86 \mu \mathrm{m}$ when increasing the fee rate from 30 to $90 \mathrm{~mm} / \mathrm{min}$, as shown in figure 9 , taking into consideration the standoff distance. It is seen that the average surface roughness improves with a low feed rate down (direct relationship). The reason for this is due to the participation of a more significant number of the higher kinetic energy of abrasive particles that cut the metals smoothly [15].

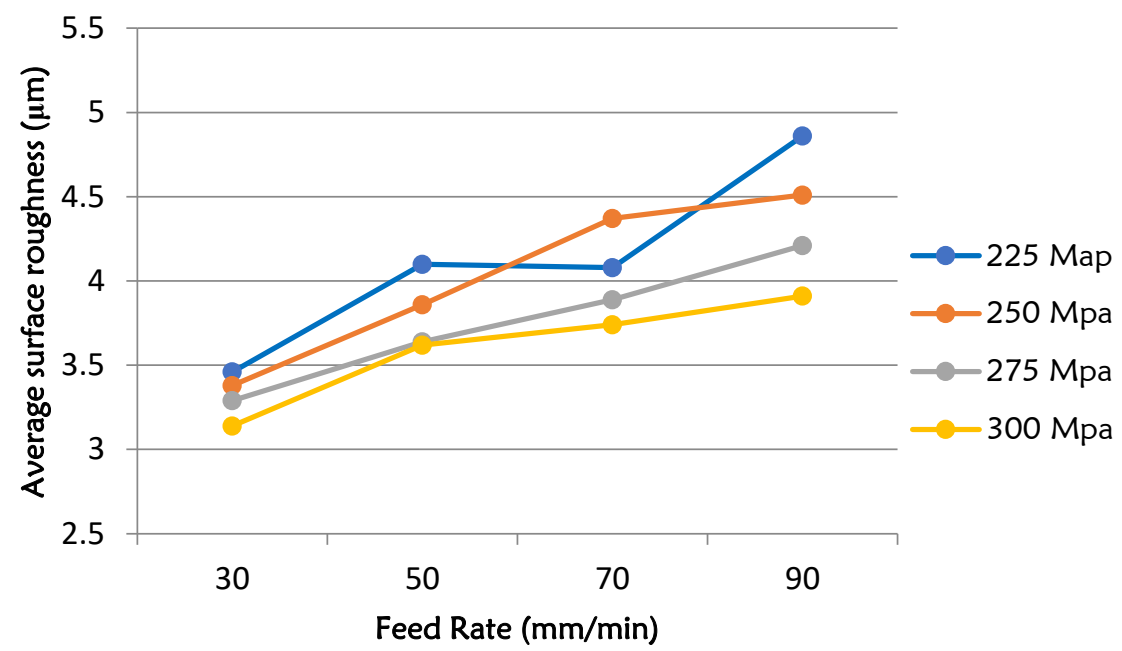

Figure 9: A plot of impact of feed rate on the average surface roughness ( $\mathrm{Ra})$.

\subsection{Influence of Standoff Distance on The Average Surface Roughness}

By conducting experiments, it's observed that average surface roughness increases from 3.14 to $4.86 \mu \mathrm{m}$ when increasing the standoff distance from 1 to $4 \mathrm{~mm}$, as shown in figure 10, taking into consideration the jet pressure. It is seen that the average surface roughness improves with a low Standoff distance down (direct relationship). The reason for this is because that rise in standoff distance produces divergence profile and scattering effect of the jet after exit of the foucsing nozzle tip, thereby decreasing the density and kinetic energy of abrasives that caused poor machining efficiency and thus provided higher surface roughness. Because of that, at lower standoff distance, the abrasives have higher density and kinetic energy, thereby cutting the workpiece smoothly and giving better surface finish [9].

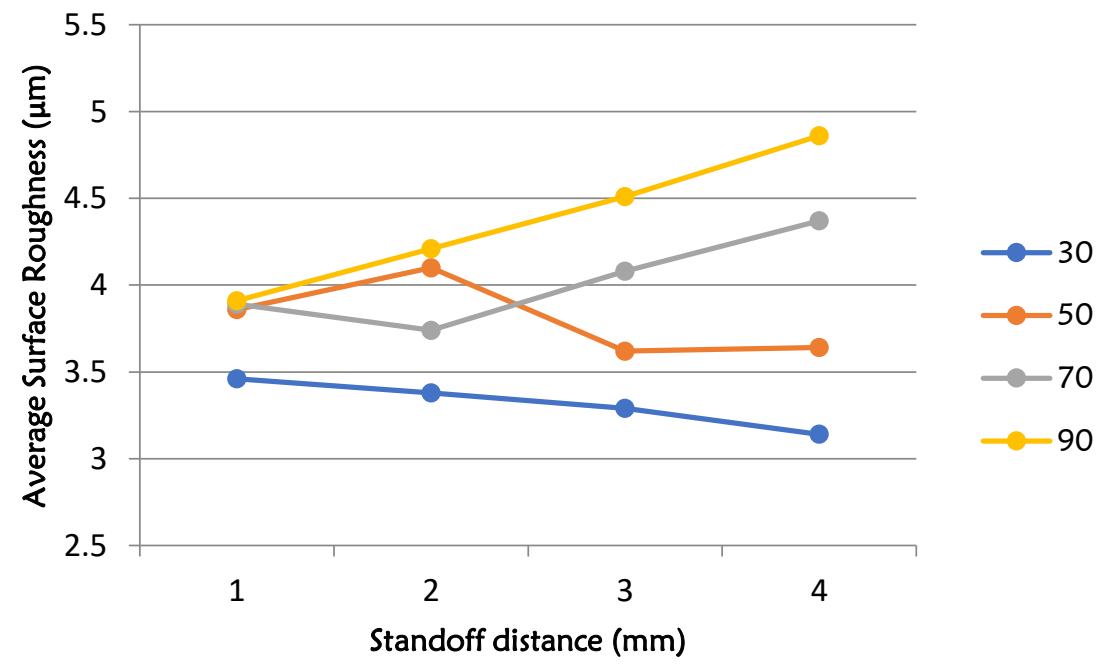

Figure 10: A plot of impact of standoff distance on the average surface roughness (Ra). 


\section{CONCLUSIONS}

From the experimental tests results and the above discussions, the following conclusions can be drawn:

1. The most significant control factors on surface roughness were Pressure jet and feed rate. Standoff distance has a lesser influence on surface roughness.

2. Average surface roughness improves with a raise in jet pressure and decreases feed rate and standoff distance; this is due to the participation of a more significant number of the higher kinetic energy of abrasive particles that cut the metals smoothly.

3. The result reveals that the jet pressure $300 \mathrm{MPa}$, the feed rate $30 \mathrm{~mm} / \mathrm{min}$ and the standoff distance of 4 $\mathrm{mm}$ are the optimal process parameters to obtain low surface roughness on carbon steel, with Ra values of $3.14 \mu \mathrm{m}$.

\section{REFERENCES}

1. Sreekesh K., Govindan P., A review on abrasive water jet, Int. J. Recent Adv. Mech. Eng. 3 (2014) $153-158$.

2. Natarajan Y., Murugesan P. K., Mohan M., Ahmed S., Abrasive Water Jet Machining process: A state of art of review. Journal of Manufacturing Processes 49 (2020) 271-322.

3. Yuvaraj N., Pradeep Kumar M., Multiresponse optimization of abrasive water jet cutting process parameters using TOPSIS approach, Mater. Manuf. Process. 30 (2015) 882-889.

4. Gupta K. J., Abrasive Water Jet Machining of Engineering Materials Springer (2020).

5. Dharmagna R. Tripathia, Krupang H. Vachhania, Soni Kumarib, Dinbandhua, Kumar Abhisheka. Experimental investigation on material removal rate during abrasive water jet machining of GFRP composites. Materials Today: Proceedings (2020).

6. Bhandarkar V., Singh V., Gupta T.V.K., Experimental analysis and characterization of abrasive water jet machining of Inconel 718. Materials Today: Proceedings (2019).

7. Mohamad W.N.F., Kasim M.S. , Norazlina M.Y, Hafiz M.S.A, Izamshah R. , Mohamed S.B., Effect of standoff distance on the kerf characteristic during abrasive water jet machining. Results in Engineering 6 (2020) 100101.

8. Bagchi A., Srivastava M., Tripathi R., Chattopadhyaya S.. Effect of different parameters on surface roughness and material removal rate in abrasive water jet cutting of Nimonic C263. Materials Today: Proceedings (2019).

9. Vasanth S., Muthuramalingam T., Vinothkumar P., Geethapriyan T., Murali G., Performance analysis of process parameters on machining titanium (Ti-6Al4V) Alloy using abrasive water jet machining process, Procedia CIRP 46 (2016) 139-142.

10. Naresh Babu M, Muthukrishnan N.,"Investigation on surface roughness in abrasive water-jet machining by the response surface method,"Mater Manuf Processes 29 (2014) 1422-8.

11. Kumar S., Gajendran S., Kesavan R., Estimation of Optimal Process Parameters for Abrasive Water JetMachining Of Marble Using Multi Response Techniques. Materials Today: Proceedings 5 (2018) 11208-11218.

12. Badgujar P.P., Rathi M.G., Taguchi Method Implementation in Abrasive Waterjet Machining Process Optimization. International Journal of Engineering and Advanced Technology (IJEAT), 3 (2014), 66-70.

13. Aultrin K.S.J., Anand M.D., Optimization of machining parameters in AWJM process for an copper iron alloy using RSM and regression analysis, Int. J. Emerg. Eng. Res. Technol. 2 (2014) 19-34.

14. Shibin R., Anandakrishnan V., Sathisha S., Sujana V.M., Investigation on the abrasive water jet machinability of AA2014 using SiC as abrasive. Materials Today: Proceedings (2019).

15. Selvan M., Raju N.M.S., H. K. Sachidanand H.K., "Effects of process parameters on surface roughness in abrasive waterjet cutting of aluminium,” Front. Mech. Eng. 2012, 7(4): 439-444.

16. Maneiah D., Shunmugasundaram M., Raji Reddy A., and Begum Z., Optimization of machining parameters for surface roughness during abrasive water jet machining of aluminium/magnesium hybrid metal matrix composites. Materials Today: Proceedings (2020)

1. 16. Jegaraj J. J. R. and Babu N. R., "A strategy for efficient and quality cutting of materials with abrasive waterjets considering the variation in orifice and focusing nozzle diameter," International Journal of Machine Tools and Manufacture, vol. 45, no. 12-13, pp. 1443-1450, Oct. 2005.

17. Khalid W., Hussain M., Nasir Bashir M., Quaz M.M., Ali I., Bhatti J., Ur Rehman H., "Development of water jet cutting and study on different parameters," Journal of Applied and Physical Sciences, vol. 5, no.3, pp. 8187, 2019.

18. El-Hofy H. A., Advanced Machining Processes, United States of America: McGraw-Hill, 2005.

19. Klichová D., Sitek L, Hloch S. Valentinčič J. ,Advances in Water Jetting Springer (2019).

20. Satyanarayana B. and Srikar G., "Optimization of abrasive water jet machining process parameters using Taguchi Grey Relational Analysis (TGRA)," International Journal of Mechanical And Production Engineering, vol. 2, no. 9, pp. 82-87, 2014.

21. Aydın G., Karakurt I.and Aydıner K., "A study on the use of Taguchi approach in AWJ machining of the granite," International Mining Congress and Exhibition of Turkey, vol. 22, pp. 111-116, 2011. 